Int. J. Electrochem. Sci., 14 (2019) 3833 - 3843

International Journal of

ELECTROCHEMICAL

SCIENCE

WWW.electrochemsci.org

\title{
Modification of Carbon Paste Electrode with Conductive Polyglycine-nafion Composite Membrane and Multi-wall Carbon Nanotubes for the Determination of Dopamine
}

\author{
Zhiqiang Wei, Runfang Liu, Dengyun Pan, Ting Li, Yuman Guo, Gaojie Ma, Hui Yang ${ }^{*}$ Sanqiang Li ${ }^{*}$ \\ Collage of Medical, Henan University of Science and Technology, Luoyang, 471023, China. \\ *E-mail: yanghui7761@ @ 163.com, sanqiangli2001@163.com
}

doi: $10.20964 / 2019.04 .21$

Received: 5 December 2018 / Accepted: 21 January 2019 / Published: 10 March 2019

\begin{abstract}
In this work, a novel method was developed to fabricate modified carbon paste electrode (CPE) by a composition of conductive polyglycine-nafion membrane and multi-wall carbon nanotubes (MWCNTs) (Poly(gly)-nafion/MWCNTs/CPE). The conductive Poly(gly)-nafion composite membrane on MWCNTs/CPE was prepared by drop-coating and in situ electrochemical polymeric deposition. Electrochemical behaviors of the fabricated electrodes were studied using cyclic voltammetry (CV) and linear sweep voltammetry (LSV). Compared with the bare CPE, Poly(gly)-nafion/MWCNTs/CPE exhibited more effective electrochemical catalytic performance for the determination of dopamine (DA). The oxidation peak current of LSV increased linearly with two concentration intervals of DA over the range of $0.1-3.0 \mu \mathrm{M}$ and 3.0-20.0 $\mu \mathrm{M}$ in BRBS with $\mathrm{pH} 5.0$ at Poly(gly)nafion/MWCNTs/CPE, and the limit of detection (LOD) was $0.03 \mu \mathrm{M}(\mathrm{S} / \mathrm{N}=3)$. Finally, the proposed method was successfully applied to detect dopamine in human serum samples.
\end{abstract}

Keywords: Carbon paste electrode, Multi-walled carbon nanotubes, Polyglycine, Nafion, Dopamine

\section{FULL TEXT}

(C) 2019 The Authors. Published by ESG (www.electrochemsci.org). This article is an open access article distributed under the terms and conditions of the Creative Commons Attribution license (http://creativecommons.org/licenses/by/4.0/). 